\title{
Erratum to: Posterior reversible encephalopathy syndrome (PRES): a rare condition after resection of posterior fossa tumors: two new cases and review of the literature
}

\author{
Lain Hermes González Quarante ${ }^{1,4}$ - José Hinojosa Mena-Bernal ${ }^{1}$ • Beatriz Pascual Martín ${ }^{1}$. \\ Marta Ramírez Carrasco $^{1}$ - María Jesús Muñoz Casado ${ }^{1}$ Ana Martínez de Aragón ${ }^{2}$. \\ Rogelio Simón de las Heras ${ }^{3}$
}

Published online: 1 March 2016

(C) Springer-Verlag Berlin Heidelberg 2016

Erratum to: Childs Nerv Syst

DOI 10.1007/s00381-015-2954-5

There's an error in the capturing of the authornames in the original publication of this article. During indexing, the authors' first family names were listed as if those were part of the authors' givenname.

So instead of:

Quarante, LHG

Mena-Bernal, JH

Martín, BPP

Carrasco, MR

Casado, MJM de Aragón, AM

de Las Heras, RS

It should have been:

Gonzalez Quarante, LH

Hinojosa Mena-Bernal, J

Pascual Martín, B

Ramírez Carrasco, M

Muñoz Casado MJ

Martínez de Aragón, A

Simón de las Heras, R

The online version of the original article can be found at http://dx.doi.org/ 10.1007/s00381-015-2954-5.

Lain Hermes González Quarante

lainhermesgq@gmail.com

1 Department of Pediatric Neurosurgery, Hospital General 12 de Octubre, Madrid, Spain

2 Department of Neuroradiology, Hospital General 12 de Octubre, Madrid, Spain

3 Department of Pediatric Neurology, Hospital General 12 de Octubre, Madrid, Spain

4 Department of Neurosurgery, HGU Gregorio Marañón, Calle Doctor Esquerdo número 46, C.P, 28007 Madrid, Spain 